\title{
The Role of Pathologic and Molecular Genetic Factors in Development of Uveal Melanoma Extrabulbar Growth
}

DOI: $10.17691 / \mathrm{stm} 2016.8 .2 .11$

Received November 20, 2015

A.lu. Tsygankov, MD, PhD, Assistant, Department of Ophthalmology";

A.G. Amiryan, MD, PhD, Leading Researcher, Department of Ocular Oncology and Radiology2;

S.y. Saakyan, MD, DSC, Professor, Head of the Department of Ocular Oncology and Radiology2; Head of the Learning Part of the Department of Ophthalmology ${ }^{1}$

Moscow State University of Medicine and Dentistry named after A.I. Evdokimov, 20/1 Delegatskaya St.,

Moscow, 127473, Russian Federation;

2 Helmholtz Moscow Research Institute of Eye Diseases, 14/19 Sadovaya-Chernogryazskaya St.,

Moscow, 105062, Russian Federation

The aim of the investigation is the disclosure of tumor extrabulbar growth association with pathologic and molecular genetic changes in patients with uveal melanoma.

Materials and Methods. 134 patients with uveal melanoma at the age of 22 to 84 years were examined and treated. The average height of the tumor was $9.2 \pm 2.9 \mathrm{~mm}$, basal diameter was $15.3 \pm 3.5 \mathrm{~mm}$. In $97.8 \%$ of cases enucleation of the affected eye was performed. Histological tumor types were spindle cell $(n=61 ; 45.6 \%)$, mixed $(n=46 ; 34.3 \%)$, and epithelioid $(n=27 ; 20.1 \%)$. Using the PCR-RFLP analysis (polymerase chain reaction-restriction fragment length polymorphism) and deletion mapping method were determined full and partial monosomy of chromosome 3 , deletions of the short arm of chromosome 1 and RASSF1A gene methylation $(n=134)$. The patients were divided into two groups: the presence $(n=15)$ and the absence $(n=119)$ of extrabulbar growth.

Results. Significantly lower rate (20 vs. $47.9 \%$ ) of spindle cell type spindle cell type in the group with extrabulbar growth is shown. The frequency of full or partial monosomy of chromosome 3 in the group with extrabulbar tumor growth was significantly higher (80 vs. $50.4 \%$ ). When comparing the groups on age and sex of the patient, the height and basal diameter, ciliary body involvement, tumor pigmentation, the presence of hemophthalmia, retinal detachment, subretinal exudate, family history, deletion of the short arm of chromosome 1 and the RASSF1A gene methylation no significant differences were found.

Conclusion. A statistically significant number of patients with uveal melanoma showed favorable tumor prognosis in the spindle cell tumor type and negative prognosis when detecting monosomy of chromosome 3 , which correlated with the extrabulbar tumor growth. To determine the relationship between the probability of extrabulbar tumor growth and other molecular genetic changes in further researches are needed.

Key words: uveal melanoma; extrabulbar growth; histological type of intraocular tumor; monosomy of chromosome 3.

Uveal melanoma - the most frequent primary intraocular malignant tumor in adult population. In Russia, its frequency varies from 6.2 to 8 new cases per 1 million of population annually [1]. There have been recorded rare cases of uveal melanoma development in children and adolescents [2]. The tumor is characterized by the aggressive course, liver and other organ distant metastases develop for five years after the treatment provided [3]. Uveal melanoma can both develop as de novo and from existing choroid nevus or hereditary oculodermal melanocytosis [4, 5]. Clinically, uveal melanoma manifests itself as a protruding round lesion on eye fundus of yellowish-brown or slategrey color (Figure 1). In some cases, uveal melanoma is accompanied by secondary retinal detachment, development of drusen and fields of orange pigment on tumor surface in result of trophic disturbances and deposition of lipofuscin granules in retinal pigment epithelium [4].

As with skin melanoma, early detection of uveal melanoma is crucial for prevention of metastatic disease development and patient death [3]. With the accumulation of data on pathogenesis of this disease, they identified risk factors for development and progression of tumor. The risk factors can be conventionally broken down into several groups: clinical, pathohistological, molecular, chromosome aberration and gene mutations. The clinical risk factors refer to age of the patient, the tumor size (height and basal diameter), involvement of the ciliary body in the neoplastic process and the extrabulbar growth [3, 6-10]. The pathohistological factors include epithelioid and mixed tumors, its anterior localization, diffuse growth nature, a large number of mitotic figures,

For contacts: Alexander lu. Tsygankov, alextsygankov1986@yandex.ru 


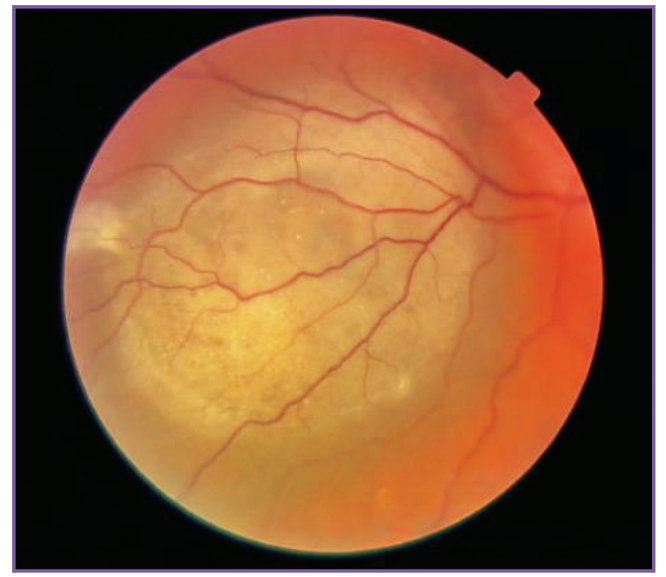

Figure 1. Uveal melanoma according to ophthalmoscopy data

moderate tumor pigmentation as well as necrotic and inflammatory components in uveal melanoma vasculature $[3,9,11]$.

The molecular prognostic factors comprise the presence of mRNA tyrosinase, vascular endothelial growth factor (VEGF), hepatocyte growth factor (HGF), and insulin-like growth factor-1 (ILGF-1) [12-15]. The risk factors of the chromosome aberration and gene mutations refer to the loss of one copy of chromosome 3 (monosomy), doubling of chromosome 8, mutation in GNAQ and GNA11 genes, CC genotype of polymorphic C3435T marker of $A B C B 1$ gene and a number of other changes [3, 10, 16-19].

In result of the growth, the uveal melanoma can "break" the hyaloid (Bruch's membrane) or adhere the retina, however, in some cases the tumor may grow towards sclera and go beyond sclerouveal ring, at the extrabulbar node is formed (Figure 2). In most cases the extrascleral invasion of the uveal melanoma is noted at large and medium tumor sizes, however, some cases of extrabulbar growth are reported at small uveal melanomas [6].

Some papers show significance of the extrabulbar growth of the tumor as a materially adverse prognostic factor which reduces the patient's life expectancy by one half due to the increased risk of hematogenous and lymphogenous dissemination of the tumor [6-8]. There are several ways of uveal melanoma invasion into the orbital cavity: via anterior and posterior ciliary arteries, vortex veins, long and shot ciliary nerves, via eye drain system (Schlemm's canal), optic nerve and via sclera perforation. At that the detection of extrabulbar growth of the uveal melanoma requires immediate enucleation of the affected eye even in case of small-size tumor [6, 7]. For determination of the vital prognosis in patients with uveal melanoma and selection of optimum tactics of surgical treatment at the initial forms of tumor the study of uveal melanoma extrabulbar growth correlation with pathologic and molecular genetic changes of the tumor

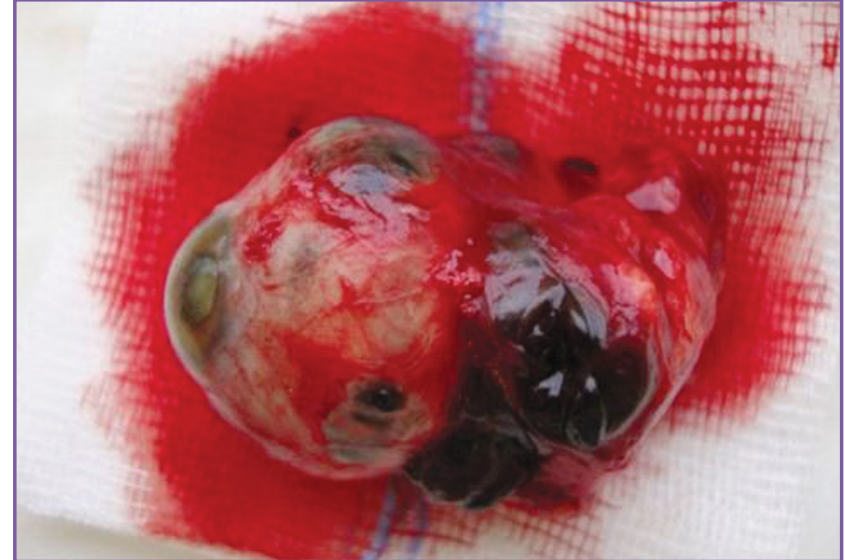

Figure 2. Enucleated eye with uveal melanoma extrabulbar node

is of some interest but the available literatures gives scarce data on that [6].

The aim of the investigation is the analysis of tumor extrabulbar growth association with pathologic and molecular genetic changes in patients with uveal melanoma.

Materials and Methods. During the period from 2005 to 2007 and in 2012, 134 patients with uveal melanoma (50 men and 84 women) at the age of 22 to 84 years (average age $52.9 \pm 11.9$ years) were examined and treated. When admitted to the hospital, all patients were subjected to the standard ophthalmological examination which included history taking, visometry, Maklakov tonometry, computer perimetry, biomicroscopy and ophthalmoscopy in mydriasis conditions, and ultrasonic examination. The height of the tumor was from 1 to $17 \mathrm{~mm}(9.2 \pm 2.9 \mathrm{~mm})$, basal diameter was from 7.3 to $21.9 \mathrm{~mm}(15.3 \pm 3.5 \mathrm{~mm})$. In the history taking they inquired if the patient had lived in unfavorable environmental conditions, had been exposed to occupational hazards, was hereditary tainted in terms of oncological diseases, co-morbidity, time interval between the first complaints and reference to a doctor.

The study complies with the Declaration of Helsinki (the Declaration was passed in Helsinki, Finland, June, 1964, and revised in October, 2000, Edinburg, Scotland) and was performed following approval by the Ethic Committee of Moscow State University of Medicine and Dentistry named after A.I. Evdokimov. Written informed consent was obtained from every patient.

According to localization the following tumors were identified: ciliary and choroid zone $(n=31 ; 23.1 \%)$, choroid ( $n=89 ; 66.4 \%)$, irido-ciliary-choroid zone $(n=10$; $7.5 \%)$, and iris $(n=4 ; 3.0 \%)$. The tumors were analyzed in a number of clinical parameters: presence $(n=31$; $23.1 \%)$ and absence $(n=103 ; 76.9 \%)$ of hemophthalmia; presence of low $(n=55 ; 41 \%)$, high $(n=39 ; 29.1 \%)$ retinal detachment and its absence $(n=40 ; 29.9 \%)$; presence $(n=34 ; 25.4 \%)$ and absence $(n=100 ; 74.6 \%)$ of subretinal 
exudate, presence $(n=30 ; 22.4 \%)$ and absence $(n=104$; $77.6 \%$ ) of the burdened familial history in terms of oncological pathology. The group formation criterion was the presence $(n=15 ; 11.2 \%$ - group 1$)$ and absence $(n=119 ; 88.8 \%$ - group 2) of tumor extrabulbar growth according to biomicroscopy, echography data as well as an incidental finding during the organ preservation treatment (brachytherapy) and enucleation (Figure 3).

In case of opaque ocular media, small size tumor, according to the indications, they carried out duplex scanning in the Doppler color flow mapping with measurement of the tumor echodensity in the area of its apex, middle and base (Figure 4), fluorescent angiography, optical coherence tomography and computerized tomography of the orbit (according to the standard technique). In the vast majority of cases $(n=131)$, according to indications, they carried out enucleation, at that in eight cases the enucleation was preceded by the organ preservation treatment (brachytherapy with $\mathrm{Rh} / \mathrm{Ru}$-applicators). In three cases they carried out organ preservation treatment (blockexcision of the tumor with the iris plasty).

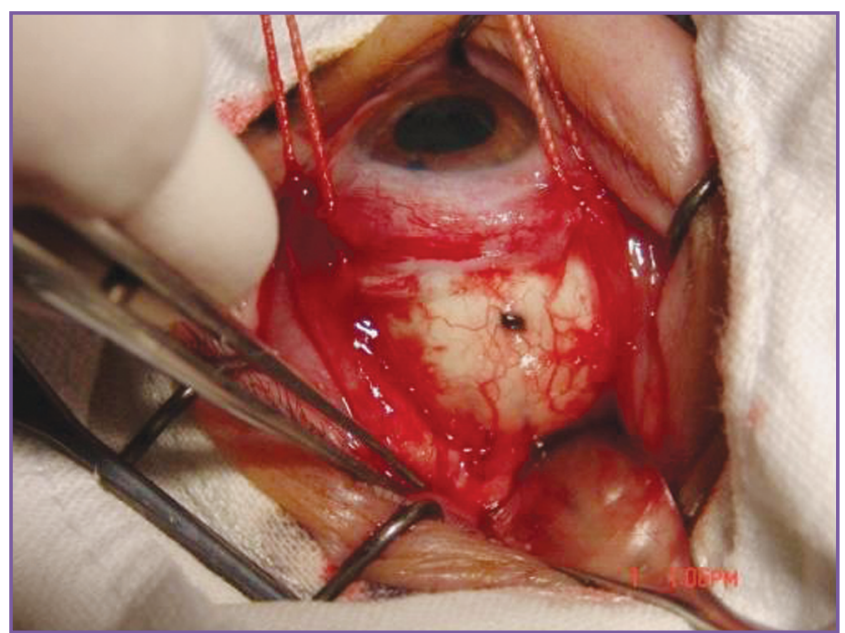

Figure 3. Intraoperative detection of uveal melanoma extrabulbar node

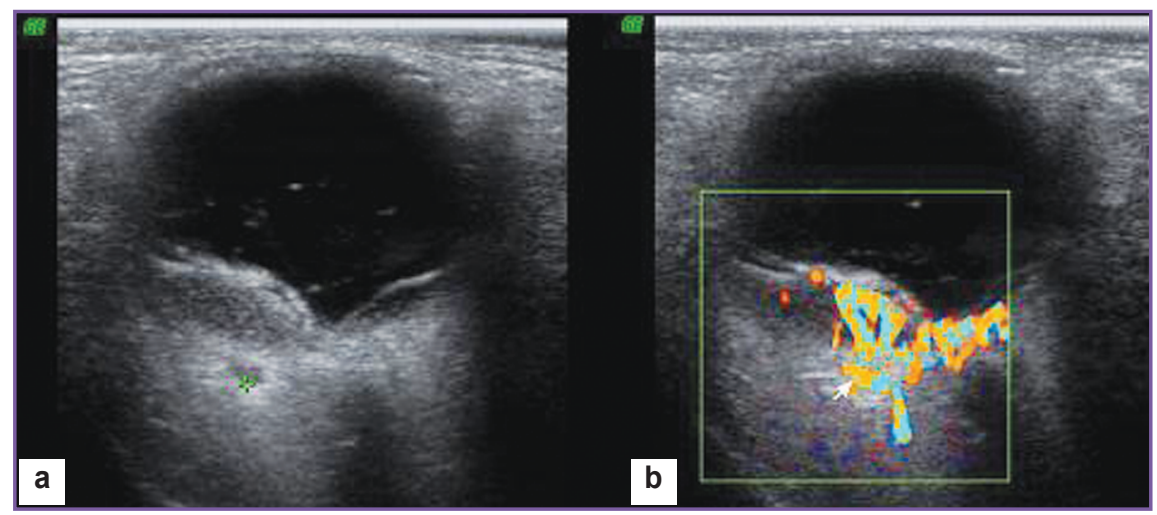

Figure 4. Extrabulbar growth of uveal melanoma: (a) sonographic image; (b) blood flow in the tumor and extrabulbar node according to the color flow mapping data
The morphologic verification was carried out in the pathologic anatomy and histology of the Helmholtz Moscow Research Institute of Eye Diseases, uveal melanoma was confirmed in all cases. According to pigment presence, they distinguished tumors with evident ( $n=59 ; 44.0 \%)$, moderate $(n=55 ; 41.0 \%)$, and low pigmentation $(n=20 ; 15.0 \%)$. Histological tumor types were spindle cell $(n=61 ; 45.6 \%)$, mixed $(n=46 ; 34.3 \%)$, and epithelioid $(n=27 ; 20.1 \%)$ (Figure 5). The presence of extrabulbar nodes of the tumor was subjected to the macro- and microscopic assessment.

In all cases, by the moment of admission to hospital, medical examination had been carried out, at that in none of the patients any lymphagland, distant organ or tissue metastasis was found.

After enucleation of the affected eye the biopsic specimen of the tumor and relatively unaffected choroid as well as specimens of peripheral blood (additive: $0.5 \mathrm{M}$ EDTA solution) were preserved at $-20^{\circ} \mathrm{C}$. For the molecular genetic testing of the specimen, the material was taken from the cytologic preparations obtained after the fine-needle aspiration.

The molecular genetic analysis which comprised determination of chromosome 3 full monosomy, deletions of the short arm of chromosome 1 and RASSF1A gene methylation was carried out in 104 patients treated in 2005-2007 on the basis of the molecular genetics laboratory of the I.M. Sechenov First Moscow State Medical University. In 30 patients treated in 2012, the analysis was carried out following the advanced method which apart of the abovementioned indicators included partial monosomy of chromosome 3 , deletion of the entire short arm of chromosome 8, mutations in GNAQ and GNA11, SEMA3B genes and polymorphism of $A B C B 1$ gene on the basis of the molecular diagnostic and genomic fingerprinting of the State Research Institute of Genetics and Selection of Industrial Microorganisms (Moscow).

The genomic DNA from tumor specimens, conventionally intact choroid and peripheral blood was extricated using proteinase $\mathrm{K}$ with subsequent phenol-chloroform extraction. In the extrication of the DNA from the cytologic preparations, the material collected from the glass was treated by the lysing buffer containing proteinase $\mathrm{K}$ and the obtained lysate was used as a matrix for the polymerase chain reaction (PCR).

The loss of heterozygosity in chromosomal regions $1 \mathrm{p} 36$, 1p31.3, 3p25.3, 3p21.3, 3p14.2, $3 q 12,3 q 26.3,3 q 28$ was identified using highly polymorphic markers D1S243, D1S2145, D1S1635, D1S407, D1S3669, D1S438, 


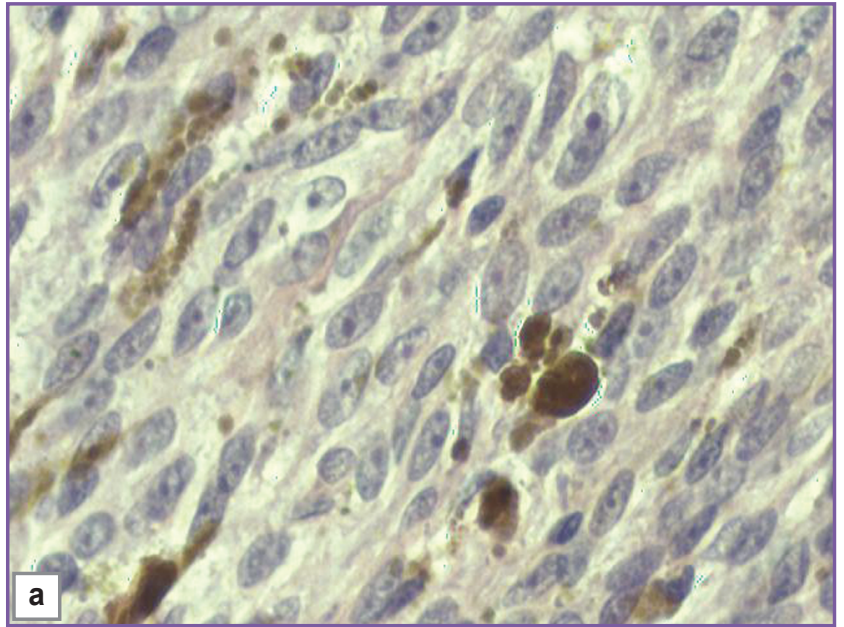

Figure 5. Uveal melanoma: (a) spindle cell; (b) mixed; (c) epithelioid; hematoxylin and eosin staining; $\times 400$

D3S1038, D3S1317, D3S1568, D3S966, D3S1300, D3S1234, D3S2459, 16xTG_3q26.31, D3S3520, D3S2398. The control was the DNA of peripheral blood leukocytes.

Methyl-sensitive PCR method was applied for determination of $\mathrm{CpG}$-islands of the genes promoter regions. The uveal melanoma cells DNA which had been pre-hydrolyzed with Hpall restrictases (for RASSF1A, $S E M A 3 B$ genes) was used as the PCR matrix. Mutations in GNAQ and GNA11 genes polymorphism of $A B C B 1$ gene was determined by the restriction fragment length polymorphism analysis method.

The follow-up period was 41-84 $(60.9 \pm 8.8)$ months for patients who were surgically operated in 2005-2007 and 13-23 $(17.4 \pm 3.1)$ months for patient who were surgically operated in 2012. The follow-up monitoring was carried out according to Russian Federation Ministry of Health Order No.135 dated April 19, 1999, once a quarter during the first year and twice a year during the second year, then once a year in the adult advisory-polyclinic department of the Helmholtz Moscow Research Institute of Eye Diseases. The patients who for various reasons failed to come for examination reported about
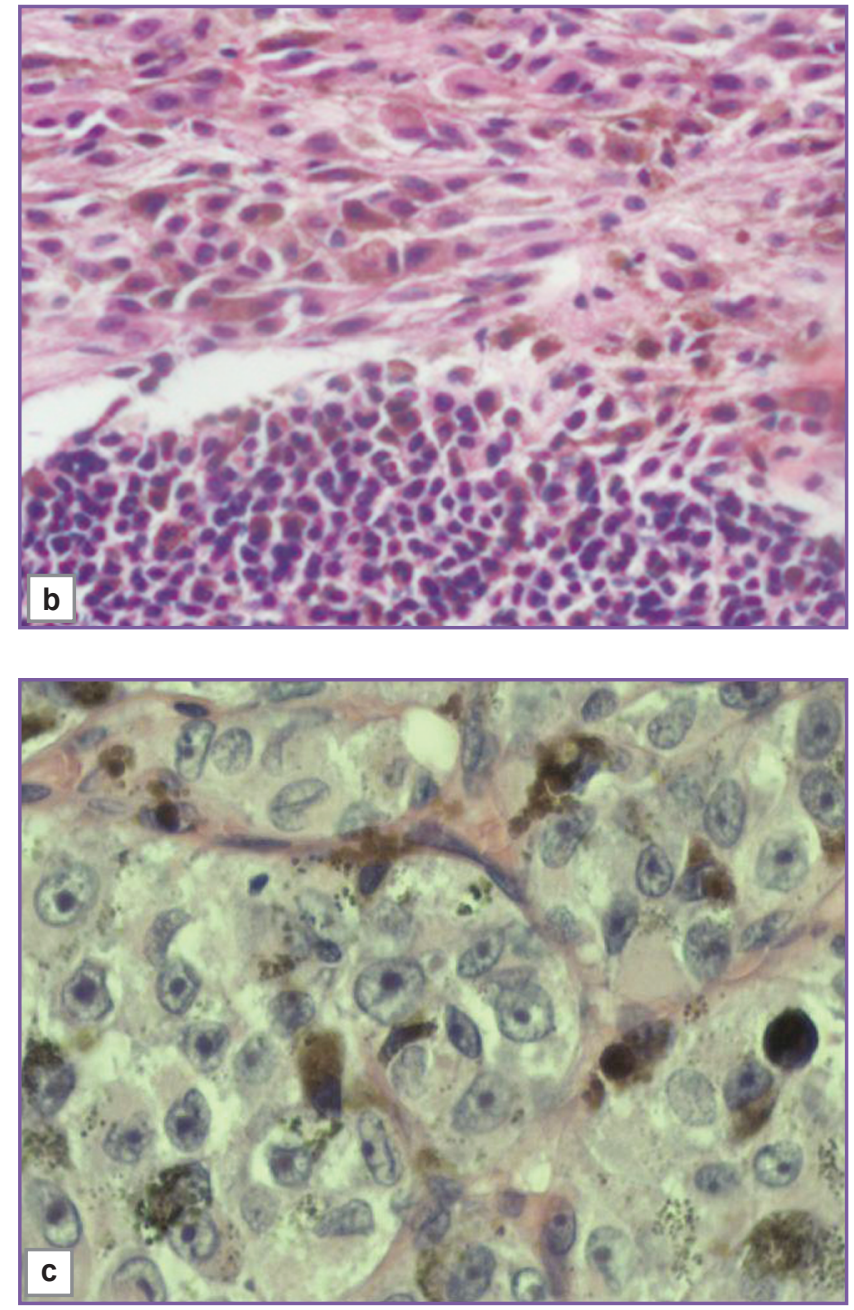

themselves by phone, fax or relatives through provision of doctor's certificates in their communities. Certain data was received by requests to the health departments in patients' communities.

The statistical processing of the results in genes polymorphism assessment was carried out using the Hardy-Weinberg's law of genetic equilibrium for autosomal characters. For comparison of genotype degree of incidence the Pearson criterion was applied and for small samples the Fisher's exact test was used. The integral assessment of the relationships between the study groups was carried out using the logistic regression and determining the odds ratio (OR) with $95 \%$ confidence interval $(\mathrm{Cl})$ and significance point equal to 0.05 . The statistically marginally relevant results $(0.05<p \leq 0.1)$ were reviewed what corresponds to $\mathrm{Cl}=94 \%$ (by contrast with the confidence interval of $95 \%$ at $p=0.05$ ). The calculations were carried out using the software package for Windows (Microsoft Excel, Statistica 10.1).

Results and Discussion. After the patients were divided into two groups with the presence (group 1) and absence (group 2) of the tumor extrabulbar growth (See the Table) the analysis of interrelations was carried 
out between the groups concerning the main clinical, pathologic and molecular genetic parameters of the tumor.

The groups were standardized by age, sex, tumor height and basal diameter. No statistically significant differences were revealed in terms of a variety of clinical and pathologic characters (pigmentation of the tumor, presence of hemophthalmia, retinal detachment, subretinal exudate, burdened familial history). The literature gives some data about negative effect of ciliary-choroid and irido-ciliary-choroid localization of the uveal melanoma in the vital prognosis and involvement of the ciliary body with the extrabulbar growth of tumor is conventionally regarded as an unfavorable predictive factor [10,11]. Our investigation revealed no interrelation between the involvement of the ciliary body and extrabulbar growth.

It should be noted that the group 1 comprises all

Clinical, pathological and molecular genetic characteristics of patients with uveal melanoma (abs. number/\%)

\begin{tabular}{|c|c|c|}
\hline Characteristics & Group 1 (n=15) & Group 2 ( $n=119)$ \\
\hline Age at the time of operation (years) & $52.5 \pm 13.9$ & $53 \pm 13.7$ \\
\hline $\begin{array}{l}\text { Sex: } \\
\text { men } \\
\text { women }\end{array}$ & $\begin{array}{c}5 / 33.3 \\
10 / 66.4\end{array}$ & $\begin{array}{l}47 / 39.5 \\
72 / 60.5\end{array}$ \\
\hline Tumor height (mm) & $9.2 \pm 2.9$ & $9 \pm 2.9$ \\
\hline Tumor basal diameter (mm) & $15.6 \pm 3.3$ & $15.5 \pm 3.2$ \\
\hline $\begin{array}{l}\text { Type of tumor: } \\
\text { spindle cell } \\
\text { mixed } \\
\text { epithelioid }\end{array}$ & $\begin{array}{l}3 / 20^{*} \\
7 / 46.7 \\
5 / 33.3\end{array}$ & $\begin{array}{l}57 / 47.9^{*} \\
39 / 32.8 \\
23 / 19.3\end{array}$ \\
\hline $\begin{array}{l}\text { Involvement of ciliary body: } \\
\text { with involvement } \\
\text { without involvement }\end{array}$ & $\begin{array}{l}6 / 40 \\
9 / 60\end{array}$ & $\begin{array}{l}35 / 29.4 \\
84 / 70.6\end{array}$ \\
\hline $\begin{array}{l}\text { Pigmentation: } \\
\text { heavily pigmented } \\
\text { lightly pigmented } \\
\text { non-pigmented }\end{array}$ & $\begin{array}{c}7 / 46.7 \\
7 / 46.7 \\
1 / 6.7\end{array}$ & $\begin{array}{l}53 / 44.5 \\
48 / 40.4 \\
18 / 15.1\end{array}$ \\
\hline Hemophthalmia & $2 / 13.3$ & $34 / 28.6$ \\
\hline Retinal detachment & $9 / 60$ & $85 / 71.4$ \\
\hline Subretinal exudate & $4 / 26.7$ & $30 / 25.1$ \\
\hline $\begin{array}{l}\text { Burdened familial history in terms } \\
\text { of oncopathology }\end{array}$ & $3 / 20$ & $27 / 22.7$ \\
\hline $\begin{array}{l}\text { Deletion of chromosome } 3 \\
\text { (full or partial monosomy) }\end{array}$ & $12 / 80^{*}$ & $60 / 50.4^{*}$ \\
\hline $\begin{array}{l}\text { Deletion of the short arm } \\
\text { of chromosome } 1\end{array}$ & $6 / 40$ & $33 / 27.7$ \\
\hline Methylation of RASSF1A gene & $2 / 13.3$ & $29 / 24.4$ \\
\hline
\end{tabular}

* differences of values between the groups are statistically significant, $p<0.05$. cases of extrabulbar growth regardless of the size of uveal melanoma nodes on the sclera surface:

single tumor cells -1 ;

single nodes on the episclera without invasion -5 ;

less than $2 \times 2 \mathrm{~mm}-2$;

from $2 \times 2 \mathrm{~mm}$ to $3 \times 4 \mathrm{~mm}-2$;

from $3 \times 4 \mathrm{~mm}$ to $4 \times 5 \mathrm{~mm}-3$;

$5 \times 7 \mathrm{~mm}-1$;

$6 \times 7 \mathrm{~mm}-1$.

The analysis of tumor cell type frequency in groups is of certain interest. Thus the frequency of the most favorable spindle cell type in the group 1 amounted to only $20.0 \%$ vs. $47.9 \%$ in the group 2 at that the differences were statistically significant $(O R=0.27$; $\mathrm{F}=0.053611 ; \xi^{2}=4.19$ ). In the paper of Amiryan et al. [6], the spindle cell tumor type was confirmed in only one case of 14 investigated cases of the uveal melanoma extrabulbar growth. However, the authors made no comparison of the histological tumor types in the groups with the presence and absence of the exrabulbar growth. Damato et al. [9] report about significantly less frequency of the spindle cell type in the group with the exrabulbar tumor growth. So, the results which we have obtained are indicative of relatively less malignancy of the uveal melanoma of the spindle cell type and its interrelation with the probability that the tumor goes beyond the sclerouveal ring. Alongside with that, they failed to reveal interrelations with the least favorable histological types of the uveal melanoma, i.e. mixed and epithelioid ones.

The analysis of molecular genetic changes revealed the statistically significant differences between the groups for the full or partial monosomy of chromosome 3 , i.e. one of the least favorable prognostic factors $[3,18$, 19] (Figure 6). No differences were revealed for such characters as deletion of the short arm of chromosome 1 or RASSF1A gene methylation. Frequency of the full or partial monosomy of chromosome 3 in the group 1 amounted to 80.0 and $50.4 \%$ in the group 2 (OR=3.93; $F=0.051573 ; \xi^{2}=4.69$ ). For the first time it was shown that chromosome 3 monosomy in tumor cells determines a higher risk of its extrabulbar growth which conditions the necessity of prompt treatment of the affected eye and thorough case monitoring. Our results are indicative of an extremely unfavorable role of chromosome 3 monosomy in the prognosis of patients with uveal melanoma, however, the order of molecular-genetic and pathologic changes in the tumor genesis remains unclear as well as the molecular mechanisms, which conditions the tumor going beyond the sclerouveal ring. Due to uniformity of the both groups, the tumor height and basal diameter did not differ significantly in this paper. Certain papers [16, 20] show that the primary mutation in GNAQ/GNA11 genes may act as a "trigger" of melanocyte malignant transformation in the tumorogenesis and consider the role of $A B C B 1$ gene polymorphism [17]. In our investigation, the analysis of mutations in the specified genes was carried out in only 30 patients, which prevents 
from drawing conclusions on the total sample. For determination of interrelation between the probability of extrabulbar tumor growth and other molecular-genetic changes (deletion of the short arm of chromosome 8, mutations in GNAQ/GNA11 genes, polymorphism of $A B C B 1$ gene) further investigations are required.

Conclusion. The investigation of pathologic and molecular genetic characteristics of the uveal melanoma in the groups with presence and absence of the extabulbar tumor growth showed significantly lower frequency $(20.0$ vs. $47.9 \%)$ of the favorable spindle cell type of the uveal melanoma in the group with the extrabulbar growth. The frequency of full or partial monosomy of chromosome 3 in the group with extrabulbar tumor growth was significantly higher $(80.0$ vs. $50.4 \%$ ). This may act as a prognostic of the uveal melanoma extrabulbar growth.

Study Funding and Conflicts of Interest. This study was not supported by any financial sources and there is no topic specific conflicts of interest related to the authors of this study.

\section{References}

1. Brovkina A.F. Oftal'moonkologiya [Ophthalmic oncology]. Moscow: Meditsina; 2002; 424 p.

2. Saakyan S.V., Amiryan A.G., Tsygankov A.Yu. Uveal melanoma in the children and adolescents: the analysis of the original observations of 21 patients. Rossiiskaya pediatricheskaya oftal'mologiya 2015; 10(3): 33-36.

3. Saakyan S.V., Amiryan A.G., Tsygankov A.Yu., Sklyarova N.V., Zaletaev D.V. Clinical, pathomorphological and molecular genetic aspects of uveal melanoma with high metastatic risk. Rossiyskiy oftal'mologicheskiy zhurnal 2015; 8(2): 47-52.

4. Brovkina A.F. Differential diagnosis of choroidal melanoma. Oftal'mologicheskie vedomosti 2008; 4(1): 68-76.

5. Shields C.L., Furuta M., Berman E.L., Zahler J.D., Hoberman D.M., Dinh D.H., Mashayekhi A., Shields J.A. Choroidal nevus transformation into melanoma: analysis of 2514 consecutive cases. Arch Ophthalmol 2009; 127(8): 981987, http://dx.doi.org/10.1001/archophthalmol.2009.151.

6. Amiryan A.G., Saakyan S.V., Valsky V.V. Extraocular extension of uveal melanoma after organ-preserving treatment. Rossiyskiy oftal'mologicheskiy zhurnal 2011; 4(3): 15-19.

7. Neroev V.V., Saakyan S.V., Amiryan A.G., Valsky V.V. Risk factors of extraocular spread after local treatment of uveal melanoma. Vestnik oftal'mologii 2011; 2: 21-25.

8. Saakyan S.V., Tsygankov A.lu., Amiryan A.G., Skljarova N.V., Zaletaev D.V. Role of molecular and genetic factors in survival from uveal melanoma. Vestnik oftal'mologii 2016; 132(1): 3-9.

9. Damato B., Coupland S.E. A reappraisal of the significance of largest basal diameter of posterior uveal melanoma. Eye (Lond) 2009; 23: 2152-2160.

10. Tsygankov A.Yu., Saakyan S.V., Amiryan A.G. The role of molecular genetic factors in survival of ciliochoroidal uveal

melanoma patients. Meditsinskiy vestnik Bashkortostana 2014; 9(2): 147-150.

11. Weis E., Shah C.P., Lajous M., Shields J.A., Shields C.L. The association between host susceptibility factors and uveal melanoma: a meta-analysis. Arch Ophthalmol 2006; 124: 5460, http://dx.doi.org/10.1001/archopht.124.1.54.

12. Frenkel S., Zloto O., Pe'er J., Barak V. Insulin-like growth factor-1 as a predictive biomarker for metastatic uveal melanoma in humans. Invest Ophthalmol Vis Sci 2013; 54(1): 490-493, http://dx.doi.org/10.1167/iovs.12-10228.

13. el Filali M., Missotten G.S., Maat W., Ly L.V., Luyten G.P., van der Velden P.A., Jager M.J. Regulation of VEGF-A in uveal melanoma. Invest Ophthalmol Vis Sci 2010; 51(5): 2329-2337, http://dx.doi.org/10.1167/iovs.09-4739.

14. Mallikarjuna K., Pushparaj V., Biswas J., Krishnakumar S. Expression of epidermal growth factor receptor, ezrin, hepatocute growth factor, and c-Met in uveal melanoma: an immunohistochemical study. Curr Eye Res 2007; 32(3): 281-290, http://dx.doi. org/10.1080/02713680601161220.

15. Pinzani P., Mazzini C., Salvianti F., Massi D., Grifoni R., Paoletti C., Ucci F., Molinara E., Orlando C., Pazzagli M., Neri B. Tyrosinase mRNA levels in the blood of uveal melanoma patients: correlation with the number of circulating tumor cells and tumor progression. Melanoma Res 2010; 20(4): 303-310, http://dx.doi.org/10.1097/cmr.0b013e32833906e3.

16. Tsygankov A.Yu., Loginov V.I., Burdennyy A.M. Mutations in oncogenes GNAQ and GNA11 in uveal melanoma patients. Molekulyarnaya meditsina 2014; 2: 34-37.

17. Saakian S.V., Amirian A.G., Tsygankov A.Yu., Loginov V.I., Burdenny A.M. Association of the ABCB1 gene with risk for uveal melanoma. Arkhiv patologii 2014, 76 (2): 3-7.

18. Prescher G., Bornfeld N., Hirche H., Horsthemke B., Jockel K.H., Becher R. Prognostic implications of monosomy 3 in uveal melanoma. Lancet 1996; 347(9010): 1222-1225, http://dx.doi.org/10.1016/s0140-6736(96)90736-9.

19. Worley L.A., Onken M.D. Person E., Robirds D., Branson J., Char D.H., Perry A., Harbour J.W, Transcriptomic versus chromosomal prognostic markers and clinical outcome in uveal melanoma. Clin Cancer Res 2007, 13(5): 1466-1471, http://dx.doi.org/10.1158/1078-0432.cer-06-2401.

20. Van Raamsdonk C.D., Griewank K.G., Crosby M.B., Garrido M.C., Vemula S. Wiesner T,, Obenauf A.C., Wackernagel W., Green G., Bouvier N., Sozen M.M., Baimukanova G., Roy R., Heguy A,, Dolgalev I., Khanin R., Busam K., Speicher M.R., O'Brien J., Bastian B.C. Mutations in GNA11 in uveal melanoma. N Engl J Med 2010; 363(23): 2191-2199, http://dx.doi.org/10.1056/nejmoa1000584. 